\title{
A General Public Study on Preferences and Welfare Impacts of Antimicrobial Resistance in the United Kingdom
}

\author{
Maria Veronica Dorgali ${ }^{1,2} \cdot$ Alberto Longo $^{1}(\mathbb{D}) \cdot$ Caroline Vass $^{3,4}\left(\mathbb{C} \cdot\right.$ Gemma Shields $^{4}\left(\mathbb{D} \cdot\right.$ Roger Harrison $^{4}$. \\ Riccardo Scarpa ${ }^{5}$ (D) Marco Boeri ${ }^{1,6}$
}

Accepted: 1 August 2021 / Published online: 30 August 2021

(c) The Author(s), under exclusive licence to Springer Nature Switzerland AG 2021

\begin{abstract}
Background Antibiotics have led to considerable increases in life expectancy. However, over time, antimicrobial resistance has accelerated and is now a significant global public health concern. Understanding societal preferences for the use of antibiotics as well as eliciting the willingness to pay for future research is crucial.

Objective To investigate preferences for different strategies to optimize antibiotic use and to understand the willingness to pay for future research in antimicrobial resistance and antimicrobial drug development.

Methods A discrete-choice experiment was administered to a sample of the UK general population. Respondents were asked to make nine choices, each offering three options-two hypothetical "doctor and antibiotics" and one "no doctor-no antibiotics" - defined by five attributes: treatment, days needed to recover, risk of bacterial infection that needs antibiotics, risk of common side effects, and risk of antimicrobial resistance by 2050. Data were analyzed using random parameters logit models. A double-bounded contingent valuation was also included in the survey to explore the willingness to pay for policies to contain antimicrobial resistance.
\end{abstract}

Results Among the 2579 respondents who completed the survey, 1151 always selected "no doctor-no antibiotics" and 57 never varied their choices; therefore, 1371 responses were used in the analysis. Risk of antimicrobial resistance by 2050 was the most important attribute and the "treatment" was the least important attribute, although this was sensitive to a higher risk of bacterial infection. The aggregate annual willingness to pay for containing antimicrobial resistance was approximately $£ 8.35$ billion ( $£ 5-£ 10$ billion).

Conclusions The antimicrobial resistance risk is relevant and important to the general public. The high willingness to pay suggests that large investments in policies or interventions to combat antimicrobial resistance are justified.

Marco Boeri

mboeri@rti.org

1 Queen's University Belfast, Belfast, UK

2 Department Statistics, Informatics, Application "G. Parenti" (DISIA), University of Florence, Florence, Italy

3 RTI Health Solutions, RTI International, Manchester, UK

4 Division of Population Health, Health Services Research \& Primary Care, The University of Manchester, Manchester, UK

5 Durham University, Durham, UK

6 RTI Health Solutions, RTI International, Forsyth House, Cromac Square, Belfast BT2 8LA, UK

\section{Key Points}

Over time, antimicrobial resistance (AMR) has accelerated, with uncontrolled use of antibiotics in both the health and agriculture sectors being important drivers in the rise in AMR, and it is currently a global public health concern.

A key step to implementing effective AMR policies that reduce overuse by engaging more with the public is to understand people's preferences, the drivers of these preferences, and the economic value placed on controlling AMR.

The risk of AMR is relevant and the most important attribute in the discrete-choice experiment and we found that the aggregate annual willingness to pay in our sample for containing AMR is approximately $£ 8.35$ billion. 


\section{Introduction}

The development of antibiotics is arguably one of the greatest public health developments of the last century, transforming medical treatment and saving many lives. The World Health Organization has estimated that antibiotics have led to an increase in life expectancy of approximately 20 years [1]. However, bacteria can rapidly become resistant, creating antimicrobial resistance (AMR), and this is threatening to make antibiotics ineffective [2]. The emergence of resistant bacteria has been attributed to antibiotic overuse: the more antibiotics that are used, the greater the risk of natural AMR to quickly develop [3]. Thus, as antibiotic use has continued to increase in absolute terms around the world, the future likelihood of their efficacy has been reducing, which will lead to longer hospital stays, increased mortality, and increased morbidity $[4,5]$.

In the UK, it is estimated that the prescribing of antibiotics by primary care physicians is highly variable, inconsistent, and often not aligned with national guidelines that aim to optimize their use [3]. In England, although there is evidence of a reduction in the number of antibiotics being prescribed, evidence of overuse still exists [6]. This overuse of antibiotics provides little clinical value, generates potential for side effects, and simultaneously contributes to the AMR crisis. The scale of the AMR crisis is colossal: estimates suggest that by 2050 AMR could result in 10 million deaths per year globally, and cumulatively costs at least $\$ 100$ trillion in hospital expenditures and productivity losses [7].

Despite rising concerns about AMR, antibiotic consumption has continued to increase [8]. Strategies to reduce the risks of AMR to humans, animals, and the ecosystem include better surveillance, improved diagnostics, new drugs, alternative treatments, and improved social conditions with primary and secondary prevention. A core element of any AMR action plan designed to curb overuse, be it at the global or national level, is to engage more with the public to raise awareness about unnecessary use [9]. For example, Public Health England launched their "Keep Antibiotics Working" campaign in 2017 with the specific aim of "raising awareness of the issue of antimicrobial resistance and reducing demand from the public" [10].

A key step in implementing effective AMR policies is understanding consumers' (or potential consumers') preferences and their drivers. The value of reducing AMR is broad and likely expands beyond simple gains to health (i.e., mortality or morbidity). Gordon et al. [11] highlight different sources of "value," including "transmission value" (the benefits of avoiding infection spread), "insurance value," (the benefits of having a treatment available as an insurance against future outbreaks), and "diversity value" (the benefits of having multiple antibiotics available that may be used within treatment strategies aiming to reduce selection pressure and minimize resistance development). Understanding the willingness to pay (WTP) for maintaining the effectiveness of antibiotics and for reducing AMR would provide a quantitative assessment of all sources of AMR's value, including those not directly classified as health.

One approach for understanding preferences and valuing health or healthcare options is the use of stated preference methods, including contingent valuation (CV) and discretechoice experiments (DCEs) [12-15]. Although DCEs are increasingly used by researchers and advocated by policy makers alike $[16,17]$, there is only a limited, but growing, literature base of preferences for AMR. A recent example by Ancillotti et al. [18] investigated the preferences of the general public in Sweden for antibiotic treatment characteristics, including an attribute "contribution to antibiotic resistance." Roope et al. [19] investigated prescribers' preferences for continued antibiotic treatment to understand how patient characteristics and prescribing pressures guide clinical choices. Similarly, in another study, Kistler et al. [20] also focused on the preferences of prescribers, whereas Mott et al. [21] elicited preferences from "patients" (individuals who had consumed antibiotics in the last 2 years for diagnostic testing to help curb AMR). Although these studies provide useful information, they do not consider the preferences of society, and they limit their focus to consumption $[19,20]$ generated by a prescriber's preferences, rather than by individuals demanding antibiotics by visiting their physician.

No previous studies have yet explored preferences for strategies to limit the use of antibiotics in the general public, nor have they assessed the monetary value to the general public of policies designed to invest in new antibiotics or to reduce the use of antibiotics in health or agricultural sectors. Understanding the attributes of AMR policies of importance to society may also help reduce unnecessary antibiotic use. For example, by introducing interventions to change behavior through the provision of tailored information based on the attributes of AMR policies most relevant to the general public.

The primary objective of the study was to investigate the impact of different strategies to limit in an optimal manner the use of antibiotics in common infections, such as a sore throat. A secondary objective was to understand the societal WTP for future research in AMR and antimicrobial drug development.

\section{Methods}

To address the stated objectives, we developed and administered a survey to collect two types of primary data. The first type was a sequence of preferred choices to a DCE, designed 
to elicit preferences and the relative importance of attributes relevant to the strategies to limit the use of antibiotics. The second type was responses from a double-bounded CV exercise. The DCE was developed and conducted according to good research practice guidelines published by the International Society for Pharmacoeconomics and Outcomes Research (ISPOR) [22].

\subsection{Study Design and Survey Development}

The study plan was reviewed and approved by the ethics review board of the School of Biological Science at Queen's University Belfast (UK). All survey respondents provided electronic informed consent.

Originally, the research team was interested in exploring respondents' WTP for policies dealing with AMR using the DCE method. However, during the survey development, it appeared impossible to include "cost" as an attribute in the DCE because most people in the UK hold the view that care from the National Health Service should be free of charge [23]. Therefore, following Mansfield et al. [24], the team used follow-up questions that explored the attributes, including cost, and addressed research questions that could not be included in the DCE. To this effect, a double-bounded CV was included in the survey to explore the WTP to fund research in AMR.

The DCE method is based on the hedonic principle that products or services comprise multiple attributes and that an individual's choice of a product or service is a function of the utility of each attribute. Thus, DCE methods can be used to elicit preferences for attributes of goods or services [16]. The development of our survey instrument was informed by a literature review and qualitative research (individual in-depth interviews) with eight participants representing experts from the Public Health Agency in Northern Ireland, clinical academics, and members of the general public. The survey included questions on respondents' past experience with antibiotics (unnecessary use, overuse, leftover), as well as questions on respondents' knowledge and attitudes toward antibiotics and antibiotic consumption, and a restricted list of the 18-item questionnaire from the Form A multidimensional health Locus of Control Scale (scores were obtained for three dimensions: internal, chance, and powerful others) $[25,26]$. In addition, respondents were provided with background information describing AMR, including the potential implications for health and healthcare, to give respondents an understanding of the topic and encourage informed decision making within the survey.

Before the survey was administered to the study sample, it was qualitatively pretested during ten in-person interviews in Belfast (UK). Generally, the pretests confirmed that the survey questions were well understood and that the attributes and the levels of the DCE questions were complete, relevant, and appropriately described. During the data collection, a preliminary data analysis of an initial sample of $100 \mathrm{com}$ pleted interviews did not lead us to make changes to the questionnaire. The final set of attributes and levels included in the DCE, which was determined based on observations from the qualitative work with experts and the general population, is summarized in Table 1 .

Before answering the DCE questions, survey respondents were explicitly asked to assume they were suffering from a hypothetical sore throat, fever with a temperature of at least $38^{\circ} \mathrm{C}\left(100.4{ }^{\circ} \mathrm{F}\right)$, discomfort or general pain, cough, or difficulty sleeping. The scenario was chosen to reflect a common health condition (e.g., upper respiratory infection) that was easily imaginable for all respondents (regardless of characteristics such as age and gender) and could potentially be associated with the misuse of antibiotics. Respondents were then presented with the option of either not going to the doctor or going to the doctor and selecting between two alternative antibiotic treatments. For each choice occasion, respondents were randomly assigned to a risk of having an antibiotic-resistant bacterial infection. Each respondent was asked to choose between alternative hypothetical profiles in a series of questions. Figure 1 presents an example of a DCE question.

The DCE survey instrument required respondents to choose their preference between the two hypothetical antibiotic treatments and the option of not going to the doctor and not taking antibiotics. In choosing their preferred option, the respondents traded off the attributes of the treatments and revealed their preferences on the relative importance of the attributes and their levels. The attribute "Risk of antibiotic-resistant infections by 2050" was included to capture the future societal impact of current individuals' choices on AMR.

As it would be impossible to show all combinations of attribute levels to each respondent, the study used a fraction of the factorial experimental design to reduce the number of choice questions to a manageable number. The fraction of the design was developed following guidelines for good research practice [27] to create the smallest number of choice tasks necessary for efficient estimation of the preference weights. The final design included 36 choice sets, which were split into four blocks; thus, each respondent was randomly assigned to one block and provided trade-offs in a sequence of nine hypothetical choice tasks. To avoid ordereffects bias, the nine choice tasks were presented in random order.

The double-bounded CV question used to estimate WTP was administered at the end of the choice task sequence. Following insights from the qualitative work with experts and the general population, the cost vector ranged between $£ 5$ and $£ 200$. The levels included in the cost vector were also discussed during pretest interviews. The payment 
Table 1 Attributes and levels

\begin{tabular}{|c|c|}
\hline Attribute label & Levels \\
\hline \multirow[t]{3}{*}{ Treatment } & $\begin{array}{l}\text { You don't go to the GP and don't take any antibiotics } \\
\text { ("no doctor" alternative specific) }\end{array}$ \\
\hline & You go to the GP who prescribes you to take antibiotics starting today \\
\hline & You go to the GP who prescribes you to take antibiotics starting in 3 days \\
\hline \multirow[t]{3}{*}{ Days until you get well and go back to your normal activities } & 10 days \\
\hline & 7 days \\
\hline & 5 days \\
\hline \multirow[t]{3}{*}{ Risk that you have a bacterial infection and you need antibiotics ${ }^{\mathrm{a}}$} & $5 \%$ ( 1 in 20 cases $)$ \\
\hline & $10 \%$ ( 1 in 10 cases $)$ \\
\hline & $20 \%$ ( 1 in 5 cases $)$ \\
\hline \multirow[t]{4}{*}{ Risk of common side effects } & None ("no doctor" alternative specific) \\
\hline & $1 \%(1$ in 100 cases $)$ \\
\hline & $5 \%$ ( 1 in 20 cases $)$ \\
\hline & $10 \%$ ( 1 in 10 cases $)$ \\
\hline \multirow[t]{4}{*}{ Risk of antibiotic-resistant infections by 2050} & $\begin{array}{l}5 \% \text { ( } 1 \text { in } 20 \text { cases will be antibiotic resistant by } 2050 \text { ) } \\
\text { ("no doctor" alternative specific) }\end{array}$ \\
\hline & $20 \%$ ( 1 in 5 cases will be antibiotic resistant by 2050 ) \\
\hline & $50 \%$ ( 1 in 2 cases will be antibiotic resistant by 2050 ) \\
\hline & $80 \%$ ( 4 in 5 cases will be antibiotic resistant by 2050 ) \\
\hline
\end{tabular}

$D C E$ discrete-choice experiment, $G P$ general practitioner

${ }^{a}$ Each DCE question was characterized by a risk of having a bacterial infection that needs to be treated with antibiotics constant across alternatives and equal to $5 \%, 10 \%$, or $20 \%$. Although this was held constant for the three alternatives in each DCE question, it was experimentally designed to vary across DCE questions

vehicle was described as an annual tax to be paid for 5 years. The CV elicited the WTP for two policies affecting the efficacy of antibiotics: (1) the public health section and (2) the agricultural-food sector. The order of the CV questions, public health section and agricultural-food sectors, was also randomized to mitigate ordering effects.

After answering the choice questions, respondents were presented with a subset of questions from the Locus of Control Scale, questions related to the "Triandis and Gelfand" Social Orientation Scale, and a series of questions to determine knowledge, experience, and perceived importance of antibiotics and bacterial infections. The final survey instrument can be found in the Electronic Supplementary Material (ESM).

\subsection{Study Population}

A sample of respondents representative of the UK general population were recruited in 2016 via Survey Sampling International (now known as Dynata), an online panel provider. Eligible panel members received a link to the online survey, programmed and hosted in Qualtrics. To be eligible, respondents had to be at least 18 years of age, residents of the UK, read the informed consent, and agree to participate.

\subsection{Statistical Analyses}

Descriptive statistics were produced to quantify the sample's key characteristics in terms of socio-demographics. Other personal characteristics, including Locus of Control Scale, Social Orientation Scale, and knowledge, experience, and perceived importance of antibiotics, were also explored and are included in the ESM.

Following research practice to address preference heterogeneity in the sample [28], the data were initially explored using random parameters logit (RPL) models with and without error components as well as latent class models. This was done to estimate a set of relative preference weights for the attribute levels included in the DCE survey that accounted for the panel nature of the data and unobserved differences in preferences across respondents. All attribute levels were effects coded so that the mean effect for each attribute was normalized at zero. Dummy-coded variables were produced for the risk of bacterial infection, as this attribute was fixed within a choice set. The final econometric specification (the RPL model with an error component) was selected based on both model fit and specification tests.

The results were used to calculate the conditional relative importance of each attribute included in the DCE and the trade-offs respondents were willing to make between attributes, as the conditional relative importance indicated 
Fig. 1 Example of a discretechoice experiment (DCE) question. Note: each DCE question was characterized by a risk of having a bacterial infection that need to be treated with antibiotics constant across alternatives and equal to $5 \%, 10 \%$, or $20 \%$. Although this was held constant for the three alternatives in each DCE question, it was experimentally designed to vary across DCE questions. $D C E$ discrete-choice experiment; $G P$ general practitione

\begin{tabular}{|c|c|c|c|}
\hline Characteristics & No Doctor & Alternative 1 & Alternative 2 \\
\hline Treatment & $\begin{array}{l}\text { You don't go } \\
\text { to the GP and } \\
\text { don't take any } \\
\text { antibiotics }\end{array}$ & $\begin{array}{l}\text { You go to } \\
\text { the GP, who } \\
\text { prescribes you to } \\
\text { take antibiotics } \\
\text { starting today }\end{array}$ & $\begin{array}{l}\text { You go to } \\
\text { the GP, who } \\
\text { prescribes you to } \\
\text { take antibiotics } \\
\text { starting in } 3 \text { days }\end{array}$ \\
\hline $\begin{array}{l}\text { Days until you get } \\
\text { well and go back } \\
\text { to your normal } \\
\text { activities }\end{array}$ & 10 days & 5 days & 7 days \\
\hline $\begin{array}{l}\text { Risk you have a } \\
\text { bacterial infection } \\
\text { and you need } \\
\text { antibiotics }\end{array}$ & $\begin{array}{c}10 \% \\
\text { (1 in } 10 \text { cases) }\end{array}$ & $\begin{array}{c}10 \% \\
\text { (1 in } 10 \text { cases) }\end{array}$ & $\begin{array}{c}10 \% \\
\text { (1 in } 10 \text { cases) }\end{array}$ \\
\hline $\begin{array}{l}\text { Risk of common } \\
\text { side effects }\end{array}$ & None & $\begin{array}{c}1 \% \\
\text { (1 in } 100 \text { cases })\end{array}$ & $\begin{array}{c}5 \% \\
\text { (1 in } 20 \text { cases) }\end{array}$ \\
\hline $\begin{array}{l}\text { Risk of antibiotic- } \\
\text { resistant } \\
\text { infections by } 2050\end{array}$ & $\begin{array}{c}5 \% \\
(1 \text { in } 20 \text { cases } \\
\text { will be antibiotics } \\
\text { resistant by } \\
2050)\end{array}$ & $\begin{array}{c}50 \% \\
\text { (1 in } 2 \text { cases will } \\
\text { be antibiotics } \\
\text { resistant by } \\
2050)\end{array}$ & $\begin{array}{c}80 \% \\
\text { (4 in } 5 \text { cases will } \\
\text { be antibiotics } \\
\text { resistant by } \\
2050)\end{array}$ \\
\hline $\begin{array}{l}\text { Which treatment } \\
\text { would you } \\
\text { choose? }\end{array}$ & & & \\
\hline
\end{tabular}

the maximum change in utility achievable when passing from the attribute level with the highest preference weight to the attribute level with the lowest preference weight [28]. Statistical analyses also included estimating the likelihood of choosing a treatment profile alternative based on specific attributes and levels of that profile.

Once the final model specification was selected, Wald and Swait-Louviere tests [29] were conducted to explore whether preferences were systematically different for different levels of risk from having a bacterial infection that needed to be treated with antibiotics (equal to $5 \%, 10 \%$, or $20 \%$ ). Specifically, we tested the significance of the interaction between each attribute level and the dummy-coded variables. This was done for two of the three levels of risk from having a bacterial infection that needed to be treated with antibiotics.

Following the standard procedure [30], the discrete response data from the double-bounded $\mathrm{CV}$ questions were analyzed using logistic regression models to estimate WTP for different AMR policies. Effects coded variables were included in the WTP regression to accommodate for heterogeneity. As part of the welfare analysis, the WTP values were aggregated to estimate a societal value. All analyses were conducted using STATA 16 [31].

\section{Results}

Overall, 2894 respondents accessed the link and 2782 consented to participate (96.1\%). In the end, 2626 started the survey, of whom 117 did not complete any of the DCE questions and were therefore excluded from all analyses. Of the remaining respondents, 2579 completed the DCE and 2518 respondents answered the CV questions. There was evidence of nontrading behavior: a total of 1151 respondents always selected the option of not going to the doctor over treatment with antibiotics. These "nontrading" respondents were excluded from the analysis, as they did not express any trade off among the attributes of interest. However, the determinants of always selecting the "no doctor" option was explored with a logistic regression to understand the effect of individual characteristics on this behavior (see Sect. 3.2.1).

Finally, 57 respondents never varied their choices (i.e., always selected either option A or option B) and were also excluded from the analysis because of concerns about their attention and engagement with the study (such an outcome is likely to occur randomly, with a probability of less than 1 in 1000). The fastest respondent completed the survey in 191 seconds, which is higher than the selected threshold of $1 / 5$ of the median time (median time $=837$ seconds 
divided by $5 \approx 167$ ). Therefore, the final active sample for the DCE analysis was 1371.

\subsection{Descriptive Statistics}

Descriptive statistics for the whole sample $(N=2579)$, for the sample used in the DCE analysis $(N=1371)$, and for respondents not included in the DCE analysis $(N=1208)$ are presented in Table 2. The last column of the table shows the Pearson chi test of independence in responses between respondents who always selected the "no doctor" alternative and respondents who also selected other alternatives. The two sample were different in terms of gender, age, and employment status. The respondents included in the DCE analysis were slightly older, female, and employed full-time.

\subsection{DCE}

\subsubsection{Respondents Who Always Selected the "No Doctor" Alternative}

The output of the logistic regression to analyze nontrading behavior is presented in Table 3. The results revealed that older respondents, single respondents (compared to other marital status), and those respondents with a higher level of education, and those who scored higher in the internal locus of control were more likely to always select the "no doctor" alternative in the DCE, while respondents who were married (compared to other marital status), and those who scored higher in the powerful others locus of control were less likely to always select the "no doctor" alternative. Respondents with a higher score on the internal Locus of Control Scale were more likely to always select the "no doctor" alternative, while respondents with a higher score on "powerful others" Locus of Control Scale were less likely to always select the "no doctor" alternative.

\subsubsection{Preference Analysis}

The final RPL included an error component and an interaction between each attribute level and dummy-coded variable for the two levels of risk of bacterial infection needing treatment with antibiotics different from the $20 \%$ risk baseline. Results are presented in Table 4. Estimated coefficients for each attribute level represent the preferences associated with the highest risk of bacterial infection requiring antibiotics $(20 \%)$. The coefficient estimates for interactions with the dummy-coded variables represent the differences in attribute preferences from the high-risk baseline of $20 \%$ that respondents associated with the lower risk levels of $5 \%$ and $10 \%$. The RPL was specified to capture both the residual effects of the error component ("no doctor" option) and interactions between the attribute levels and the level of bacterial infection. Preference heterogeneity is captured by a zero-mean normal distribution for each preference coefficient (assumed to be the same across different levels of risk).

Figure 2 illustrates the conditional attribute relative importance. These are computed as the difference between the most and least preferred attribute level. To facilitate the comparison in the interacted model, the relative importance for each attribute was normalized dividing by the sum of the relative importance of all attributes and multiplied by 100 .

The ordering of preferences largely aligns with a priori expectations, with risk of AMR by 2050 being the most important and the "treatment" attribute being the least important. However, when presented with the highest risk of infection (20\%), respondents were less concerned about AMR than when presented with the lowest risk (5\%). When presented with the highest risk of infection (20\%), respondents placed more importance on the number of days needed to recover than when presented with the lowest risk (5\%). When presented with a $10 \%$ risk of bacterial infection, respondents were more likely to select alternatives with a 3 -day wait on the prescription before starting antibiotics and they considered more carefully (placing more importance on) the risk of common side effects. The results of the preference analysis revealed that preferences were systematically different for different levels of risk of bacterial infection needing treatment with antibiotics.

\subsection{Welfare Analysis}

When asked through the CV question whether they would pay toward a fund to be spent on improving the use and efficacy of antibiotics in both the public health sector and the agricultural-food sector, more than $50 \%$ of respondents would vote in favor of a policy to fund research to improve efficacy in the use of antibiotics. Table 5 presents results from the double-bounded contingent valuation model including covariates to accommodate for preference heterogeneity. As effects-coded covariates were included in the model, the constant can be interpreted as the average WTP, and the coefficients on the covariates can be interpreted as the differences in WTP from the average WTP in the sample for specific groups of respondents. Therefore, the estimate for the average WTP was $£ 87$ for increasing the efficient use of antibiotics in public health settings and $£ 82$ in the agricultural-food sector for 5 years per household (see Table 5).

Respondents who always selected the "no doctor" option in the DCE and respondents who consider AMR a very serious threat to their country had a significantly lower WTP for improvements in health, while respondents who consider AMR very serious for their family and future generations had a significantly higher WTP for improvements in both public health and agricultural-food sectors. Interestingly, 
Table 2 Respondent characteristics and comparison between full sample and respondents included in the DCE analysis (Fisher Exact Test)

\begin{tabular}{|c|c|c|c|c|}
\hline Question & $\begin{array}{l}\text { Included in the DCE } \\
\text { Analysis }(n=1371), n \\
(\%)\end{array}$ & $\begin{array}{l}\text { Not included in the DCE } \\
\text { Analysis }(n=1208), n(\%)\end{array}$ & $\begin{array}{l}\text { Full sample } \\
(N=2579), n \\
(\%)\end{array}$ & $\begin{array}{l}P \text {-value } \\
(\text { Cramer V) }\end{array}$ \\
\hline \multicolumn{5}{|l|}{ What is your gender? } \\
\hline Female & $730(53.3)$ & $564(46.7)$ & $1294(50.2)$ & \multirow[t]{3}{*}{$<0.001(0.26)$} \\
\hline Male & $640(46.7)$ & $644(53.3)$ & $1284(49.8)$ & \\
\hline Did not answer & $1(0.1)$ & $0(0.0)$ & $1(0.0)$ & \\
\hline Age, mean (SD), year & $52.0(17.6)$ & $44.9(18.4)$ & $48.3(18.4)$ & $<0.001(0.14)$ \\
\hline \multicolumn{5}{|c|}{ What is the highest level of education you have completed? } \\
\hline Less or some high school & $108(8.3)$ & $96(8.0)$ & $204(8.1)$ & \multirow[t]{6}{*}{$0.11(0.07)$} \\
\hline High school or equivalent (e.g., GED) & $309(23.8)$ & $306(25.5)$ & $615(24.6)$ & \\
\hline Some college but no degree & $273(21.0)$ & $205(17.1)$ & $478(19.1)$ & \\
\hline Technical school or college degree (e.g., BA, BS) & $460(35.3)$ & $428(35.7)$ & $888(35.5)$ & \\
\hline Graduate degree (e.g., MBA, MS, MD, PhD) & $151(11.6)$ & $165(13.8)$ & $316(12.6)$ & \\
\hline Did not answer & $70(5.1)$ & $8(0.7)$ & $78(3.0)$ & \\
\hline \multicolumn{5}{|c|}{ Which of the following best describes your employment status? } \\
\hline Employed (full-time or part-time) & $675(51.6)$ & $494(41.1)$ & $1169(46.5)$ & \multirow[t]{7}{*}{$<0.001(0.16)$} \\
\hline Self-employed & $67(5.1)$ & $76(6.3)$ & $143(5.7)$ & \\
\hline Homemaker & $98(7.5)$ & $95(7.9)$ & $193(7.7)$ & \\
\hline Student & $74(5.7)$ & $41(3.4)$ & $115(4.6)$ & \\
\hline Retired & $271(20.7)$ & $401(33.3)$ & $672(26.8)$ & \\
\hline Unemployed or unable to work & $123(9.4)$ & $97(8.0)$ & $220(8.7)$ & \\
\hline Did not answer & $64(0.05)$ & $4(0.3)$ & $68(2.6)$ & \\
\hline \multicolumn{5}{|c|}{ What was the total household income last fiscal year (before taxes)? } \\
\hline Less than $£ 24,999$ & $584(44.9)$ & $503(41.8)$ & $1087(43.4)$ & \multirow[t]{5}{*}{$0.316(0.06)$} \\
\hline$£ 25,000-£ 49,999$ & $509(39.2)$ & $488(40.6)$ & $997(39.8)$ & \\
\hline$£ 50,000-£ 99,999$ & $184(14.1)$ & $177(14.7)$ & $361(14.4)$ & \\
\hline$£ 100,000$ or more & $24(1.8)$ & $34(2.8)$ & $58(2.3)$ & \\
\hline Did not answer & $70(5.1)$ & $6(0.5)$ & $76(2.9)$ & \\
\hline
\end{tabular}

$B A$ Bachelor of Arts, $B S$ Bachelor of Science, $D C E$ discrete-choice experiment, GED general education degree, $M B A$ Master of Business Administration, $M D$ Medical Doctor, $M S$ Master of Science, $P h D$ Doctor of Philosophy, $S D$ standard deviation

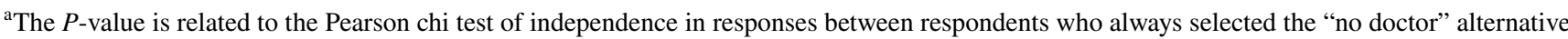
and respondents who also selected other alternatives (only the latter were included in the DCE)

Table 3 Logistic regression for respondents who always selected the "no doctor" alternative $(N=2579)$

\begin{tabular}{lllll}
\hline Variable & Coeff. & P-value & \multicolumn{2}{c}{$\begin{array}{l}\text { 95\% confidence } \\
\text { interval }\end{array}$} \\
\hline Constant & & \multicolumn{3}{c}{0.91} \\
Age & 0.23 & 0.520 & -0.46 & 0.02 \\
Higher education & 0.02 & $<0.001$ & 0.01 & 0.23 \\
Single & 0.07 & 0.402 & -0.09 & 0.29 \\
Married & 0.17 & 0.007 & 0.05 & -0.03 \\
Number of children (age < 16 years) & -0.14 & 0.010 & -0.24 & 0.20 \\
Internal Locus of Control Scale score & 0.11 & 0.014 & 0.02 & 0.12 \\
Chance Locus of Control Scale score & 0.08 & $<0.001$ & 0.03 & 0.04 \\
Powerful others Locus of Control Scale score & -0.01 & 0.791 & -0.05 & -0.22 \\
\hline
\end{tabular}

Coeff. coefficient

Note: the multidimensional health Locus of Control Scale is an 18-item self-report questionnaire designed to assess an individual's preferred control orientation with respect to health. A restricted list of the 18 items from Form A was used. Scores were obtained for three dimensions: internal, chance, and powerful others (obtained by summing across items associated with those subscales appropriate for Form A identified by Wallston et al., 1994 [26]) 
Table 4 Random parameters logit error component with interaction for the differences in risk of infection $(N=1371)$

\begin{tabular}{|c|c|c|c|c|c|c|c|c|c|}
\hline \multirow[t]{2}{*}{ Attribute } & \multicolumn{2}{|c|}{$\begin{array}{l}\text { Highest risk (base- } \\
\text { line 20\%) }\end{array}$} & \multicolumn{2}{|c|}{$\begin{array}{l}\text { Medium risk (treat- } \\
\text { ment }=10 \% \text { ) }\end{array}$} & \multicolumn{2}{|c|}{$\begin{array}{l}\text { Lowest risk (treat- } \\
\text { ment }=5 \% \text { ) }\end{array}$} & \multicolumn{3}{|c|}{$\begin{array}{l}\text { Standard deviation of the } \\
\text { normal distribution }\end{array}$} \\
\hline & Estimate & Std. err. & Estimate & Std. err. & Estimate & Std. err. & Estima & & Std. err. \\
\hline \multicolumn{10}{|l|}{ Treatment } \\
\hline Go to the GP and start antibiotics today & & 0.065 & 0.03 & $-0.141 * * *$ & 0.04 & -0.035 & 0.04 & \multicolumn{2}{|c|}{$0.414 * * * 0.03$} \\
\hline Go to GP and start antibiotics in 3 days & & -0.065 & 0.03 & & & & & & \\
\hline \multicolumn{10}{|l|}{ Days until one can go back to normal activities } \\
\hline Back to normal in 5 days & & 0.425 & 0.06 & $-0.24 * * *$ & 0.07 & $-0.294 * * *$ & 0.08 & \multicolumn{2}{|c|}{$0.502 * * * 0.03$} \\
\hline Back to normal in 7 days & & -0.091 & 0.05 & $0.172 * * *$ & 0.07 & 0.100 & 0.08 & 0.037 & 0.08 \\
\hline Back to normal in 10 days & & -0.333 & 0.05 & & & & & & \\
\hline \multicolumn{10}{|l|}{ Risk of common side effects } \\
\hline $1 \%$ risk & & -0.080 & 0.067 & $0.292 * * *$ & 0.08 & $0.177 * *$ & 0.08 & -0.047 & 0.08 \\
\hline $5 \%$ risk & & 0.069 & 0.041 & $-0.122 * *$ & 0.06 & $-0.106^{*}$ & 0.06 & -0.010 & 0.13 \\
\hline $10 \%$ risk & & 0.011 & 0.053 & & & & & & \\
\hline \multicolumn{10}{|l|}{ Risk of antibiotic-resistant infections by 2050} \\
\hline $20 \%$ risk & & 0.237 & 0.06 & 0.029 & 0.08 & $0.284 * * *$ & 0.08 & \multicolumn{2}{|c|}{$0.581 * * * 0.04$} \\
\hline $50 \%$ risk & & -0.030 & 0.05 & $0.117 *$ & 0.07 & $-0.196 * * *$ & 0.07 & 0.085 & 0.13 \\
\hline $80 \%$ risk & & -0.208 & 0.05 & & & & & & \\
\hline "No doctor" alternative & 0.775 & 0.08 & 0.008 & 0.10 & 0.002 & 0.08 & & & \\
\hline Sigma (error component) & $1.985 * * *$ & 0.06 & & & & & & & \\
\hline Log-likelihood & $-11,010.76$ & & & & & & & & \\
\hline
\end{tabular}

$D C E$ discrete-choice experiment, GP general practitioner, Std. err. standard error

Note: levels of significance: $* P<0.1 ; * * P<0.05$; *** $P<0.01$.

Note: each DCE question was characterized by a risk of having a bacterial infection that need to be treated with antibiotics constant across alternatives and equal to 5\% (lower risk), $10 \%$ (medium risk), or 20\% (higher risk, baseline). Although this was held constant for the three alternatives in each DCE question, it was experimentally designed to vary across DCE questions

Fig. 2 Conditional attribute relative importance $(N=1371)$. Note: each discrete-choice experiment question was characterized by a risk of having a bacterial infection that need to be treated with antibiotics constant across alternatives and equal to $5 \%, 10 \%$, or $20 \%$. Although this was held constant for the three alternatives in each discrete-choice experiment question, it was experimentally designed to vary across discrete-choice experiment questions. The vertical bars surrounding each mean relative importance denote the $95 \%$ confidence interval (computed by delta method)

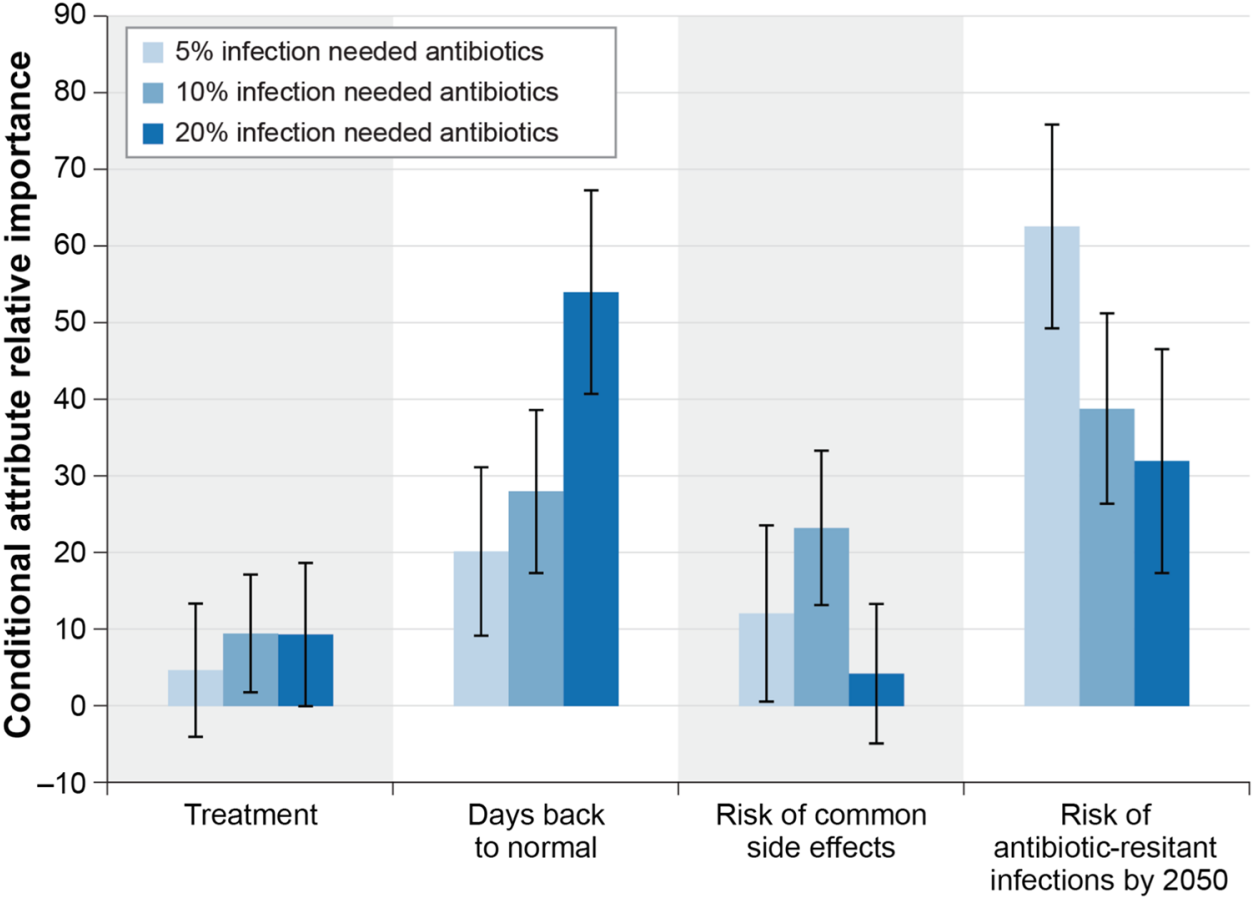


the personal characteristics driving WTP for improvements in public health and agricultural-food sectors are different (i.e., different coefficients in the first three columns and the next three columns of Table 5).

\section{Discussion}

This study contributes to a growing, yet still quite limited, body of evidence on preferences for antibiotic treatments $[18,19,21]$. Understanding the societal preferences for the attributes of future approaches to combat AMR should help policy makers develop future AMR strategies to consumers and potential consumers of treatment.

In respondents who made trade-offs, the risk of infection and the risk of AMR in the future (2050, for the purposes of this study) were both shown to impact preferences and how people react to infections by using antibiotics. Further evidence that the risk of AMR is relevant and important to the public is the estimated WTP. With 19.2 million households in the UK, and an average annual WTP for containing AMR of approximately $£ 87$ per household, the total annual WTP for 5 years was found to be approximately $£ 8.35$ billion ( $£ 87 \times 19.2$ million households in the $\mathrm{UK} \times 5$ years). This figure varies between 5 and 10 billion for 5 years (1-2 billion per year) depending on the covariates considered. This suggests that policies to combat AMR or research of new antibiotics are of high value to society, and policy makers may consider financial incentives and subsidies to encourage AMR-reducing behavior or scientific research.
For comparison, the Department of Health spent $£ 4.5$ million on a national campaign to raise awareness of colorectal cancer and $£ 2.9$ million on a campaign to raise awareness of non-small-cell lung cancer [32, 33]. In addition to public health measures, policy makers may seek to implement fiscal policies (i.e., taxes or subsidies as disincentives or incentives, respectively). As education was correlated with WTP, it could be worthwhile pursuing policies that raise awareness of AMR, such as public education or engagement activities.

A higher score on the internal Locus of Control Scale, indicating a higher belief by respondents that they can affect their own health, was associated with an increased likelihood of always selecting the "no doctor" alternative, while respondents with a higher score on the "powerful others" Locus of Control Scale, implying that their own health depends mostly on decisions taken by others such as doctors, were less likely to always select the "no doctor" alternative. Although the health controls of the general population are not known, it may be important to understand that attitudes toward health may be associated with preferences for AMR. The results of this study contribute to a growing literature examining the relationship between individuals' beliefs and their health behaviors and decision making $[34,35]$.

Concerns about AMR were an important driver of preferences and WTP. Respondents who consider AMR very serious for their family and future generations were more likely to opt out of treatment and had higher WTP for AMR policies in both public health and agricultural-food domains. Policy makers seeking to create AMR campaigns to increase knowledge and raise awareness of resistance may consider
Table 5 Double-bounded regression on the contingent valuation questions in willingness-to-pay space $\left(N=2570^{\mathrm{a}}\right)$

\begin{tabular}{|c|c|c|c|c|c|c|}
\hline \multirow[t]{2}{*}{ Variable } & \multicolumn{3}{|c|}{$\begin{array}{l}\text { Increase efficient use of } \\
\text { antibiotics in health }\end{array}$} & \multicolumn{3}{|c|}{$\begin{array}{l}\text { Increase efficient use of } \\
\text { antibiotics in agri-food }\end{array}$} \\
\hline & Coeff. & $95 \% \mathrm{CI}$ & & Coeff. & $95 \% \mathrm{CI}$ & \\
\hline Constant & $87.12^{*}$ & 74.21 & 100.03 & $81.77^{*}$ & 68.82 & 94.72 \\
\hline Always selected "no doctor" in DCE & $-6.06^{*}$ & -10.32 & -1.81 & -3.47 & -7.76 & 0.82 \\
\hline Age & $-0.36^{*}$ & -0.61 & -0.10 & -0.22 & -0.48 & 0.03 \\
\hline Female & $-6.37^{* \&}$ & -10.73 & -2.01 & $-6.41^{*}$ & -10.80 & -2.03 \\
\hline Married & -0.55 & -4.80 & 3.69 & 1.30 & -2.98 & 5.57 \\
\hline No children in household & 3.78 & -2.28 & 9.83 & 4.46 & -1.64 & 10.56 \\
\hline Higher education & $6.76^{*}$ & 2.56 & 10.96 & $9.16^{*}$ & 4.92 & 13.40 \\
\hline AMR threat very serious for my family & $14.03^{*}$ & 6.31 & 21.76 & $7.75^{*}$ & 0.06 & 15.43 \\
\hline AMR threat very serious for my country & $-10.32^{*}$ & -18.48 & -2.17 & -2.77 & -10.89 & 5.35 \\
\hline AMR threat very serious for the world & $6.52^{*}$ & 0.75 & 12.29 & 4.20 & -1.60 & 10.00 \\
\hline AMR threat very serious for future generations & $12.45^{*}$ & 7.56 & 17.34 & $16.41^{*}$ & 11.47 & 21.35 \\
\hline Sigma & $89.55^{*}$ & 84.92 & 94.18 & $89.99^{*}$ & 85.29 & 94.69 \\
\hline
\end{tabular}

Agri agricultural, AMR antimicrobial resistance, Coeff. coefficient, $C I$ confidence interval, DCE discretechoice experiment

${ }^{a}$ Nine respondents did not answer at least one of the questions used to create the covariate in the logistic regression and therefore were excluded from this analysis

*Significant at least a $5 \%$ level 
explaining the future threat to combat overuse. Combatting overuse of antibiotics is more urgent than ever, as recent research suggests that the COVID-19 pandemic may have contributed to unnecessary use, increasing resistant infections by as much as $10 \%[36,37]$.

We are aware of only one other study specifically investigating the general public's preferences: Ancillotti et al. [18] conducted a study with 378 members of the Swedish public. Although the studies are different, the results are comparable. Both studies found evidence of preference heterogeneity, a strong relative importance on AMR, and a low relative importance of treatment duration/time to feel back to normal. Ancillotti and colleagues found younger respondents to be more concerned with AMR, whereas our results suggest older participants to be more likely to choose "no doctor" and forgo treatment. Our finding aligns with the results reported by Napolitano et al. [38] who found younger people to be more likely to take antibiotics without a prescription. Our results also revealed age to have a statistically significant negative effect on WTP for AMR policies (i.e., older respondents had a lower WTP).

Ancillotti and colleagues [18] incorporated a cost attribute in their DCE to directly estimate WTP for a reduction in antibiotic resistance, identifying a mean WTP of approximately $€ 88$ (approximately £80) to reduce AMR from "high" to "low." The magnitude of their estimate is very close to the individual WTP estimate of approximately £82-£87 per year estimated from our $\mathrm{CV}$ data. Although stated preference studies conducted with different samples and different attributes cannot easily be compared, such similarity of results corroborates the validity of our results.

This study, however, suffers from a number of limitations, with self-selection being arguably the most serious and the most difficult to correct. Notably, while respondents were recruited via a reputable marketing firm of panel providers, careful quotas were imposed to ensure representativeness. Nevertheless, whether the sample of panel members reflects the general population remains unknown [39]; furthermore, the survey was administered online [40], potentially resulting in a sample more intrinsically motivated in AMR than the wider public. Furthermore, respondents received detailed information about AMR during the survey to help provide the context for the choice scenarios presented in the DCE. Future research may explore how preferences for AMR policies change with knowledge and information of AMR.

Non-trading behavior (where the respondent always chooses the same option in each choice set) can be a concern in the analysis of preference data, particularly if it is unclear whether respondents are selecting the option because it is truly utility maximizing [41]. However, in this study, the sample size was sufficient to analyze the preference data on the trading sample alone, avoiding the bias associated with including non-trading respondents that could impact the estimated $\beta$-coefficients (i.e., including those who consistently rejected the doctor alternatives means they would also reject all side-effect levels and all opportunities to get well faster).

Although a power calculation was not conducted for this study, the sample of over 1000 respondents, completing nine questions each, suggests our study is unlikely to be underpowered [42]. As with many DCE studies, investigation of external validity was not possible; however, there is some evidence to suggest that stated preferences and revealed preferences (obtained through monitoring subsequent appointments) do align in some cases [43].

\section{Conclusions}

As AMR continues to be a key global public health concern, understanding what are the treatment attributes that drive consumption may be important to healthcare decision makers seeking to reduce use. This study identified that the UK general public consider time to improvement, risk of side effects, and the chance of antibiotic-resistant infections as important attributes in their decisions about antibiotic treatment. A significant proportion of the population $(45.7 \%)$ would also choose "no doctor" and forgo treatment in all presented choice scenarios. Overall, among respondents making trade-offs, the most important treatment attribute was AMR when the risk of infection was $5-10 \%$, suggesting that antibiotic resistance is perceived as a key concern. Respondents who considered AMR to be a very serious future threat were also more likely to opt out of treatment. Decision makers should consider continuing AMR campaigns designed to raise awareness among the general public. The results of this study also suggest investment in AMR policies are worthwhile, even if they are expensive, as they have a high societal value estimated in the UK of $£ 6-£ 8$ billion per year.

Supplementary Information The online version contains supplementary material available at https://doi.org/10.1007/s40273-021-01076-9.

\section{Declarations}

Funding This research was part of the "Exploring Antimicrobial Resistance From a Societal Viewpoint: Tools From Welfare Economics and Preference Analysis" Project, awarded as a Wellcome Trust Seed Award in Humanities and Social Science in 2015.

Conflicts of Interest/Competing Interests The authors have no conflict of interest to declare.

Ethics approval Approval was obtained from the School of Biological Science at Queen's University Belfast. The procedures used in this study adhere to the tenets of the Declaration of Helsinki. The research was carried out in compliance with national laws protecting respond- 
ents' personal data and with the Codes of Conduct of the European Society for Opinion and Market Research, the European Pharmaceutical Marketing Research Association, and the British Healthcare Business Intelligence Association.

Consent to Participate At the beginning of the survey, respondents were asked to explicitly give consent to participate in the study. No clinical data were collected in this study.

Consent for Publication The consent form included the use of data in aggregated manner for publication.

Availability of Data and Material The data sets generated and analyzed during the current study are available from the corresponding author on reasonable request.

Code Availability The code is available on request from the corresponding author.

Authors' Contributions $\mathrm{MB}$ secured the funding. MB VD, and $\mathrm{AL}$ developed the survey instrument, collected the data, and executed the analysis. VD and MB led the development of the manuscript, with input from CV. All authors contributed to drafting and revising the manuscript, gave final approval of the version to be published, and agree to be accountable for all aspects of the work.

Previous Presentation The initial output of this work was presented as a poster at Virtual ISPOR Europe 2020; 16-19 November, 2020.

\section{References}

1. WHO. Self-prescription of antibiotics boosts superbugs epidemic in the European region. 2012. https://www.euro.who.int/en/ media-centre/sections/press-releases/2012/11/self-prescriptionof-antibiotics-boosts-superbugs-epidemic-in-the-european-region. Accessed 27 Feb 2021.

2. Ventola CL. The antibiotic resistance crisis: causes and threats. $P$ T J. 2015;40(4):277-83.

3. Palin V, Mölter A, Belmonte M, et al. Antibiotic prescribing for common infections in UK general practice: variability and drivers. J Antimicrob Chemother. 2019;74(8):2440-50.

4. WHO. Antibiotic resistance: key facts. 2020. https://www.who. int/news-room/fact-sheets/detail/antibiotic-resistance. Accessed 27 Feb 2021.

5. Cecchini M, Langer J, Slawomirski L. Antimicrobial resistance in G7 countries and beyond: economic issues, policies and options for action. Paris: Organization for Economic Co-operation and Development; 2015: p. 1-75.

6. Sun X, Gulliford MC. Reducing antibiotic prescribing in primary care in England from 2014 to 2017: population-based cohort study. BMJ Open. 2019;9(7):e023989.

7. O'Neil J. Tackling drug-resistant infections globally: final report and recommendations. Analysis \& Policy Observatory. 2016. https://apo.org.au/node/63983. Accessed 28 Jul 2021.

8. Van Boeckel TP, Gandra S, Ashok A, et al. Global antibiotic consumption 2000 to 2010: an analysis of national pharmaceutical sales data. Lancet Infect Dis. 2012;13(6202):1057-98.

9. WHO. Global action plan on antimicrobial resistance. 2015. https://www.who.int/publications/i/item/9789241509763. Accessed 28 Jul 2021

10. Public Health England. Keep antibiotics working. https://campa ignresources.phe.gov.uk/resources/campaigns/58-keep-antibiotics-working/Overview. Accessed 22 Jun 2021.
11. Gordon J, Darlington O, McEwan P, et al. Estimating the value of new antimicrobials in the context of antimicrobial resistance: development and application of a dynamic disease transmission model. Pharmacoeconomics. 2020;38(8):857-69.

12. NOAA. Natural resource damage assessments under the Oil Pollution Act of 1990. Fed Gov Fed Regist. 1993.

13. Boxall PC, Adamowicz W, Swait J, Williams M, Louviere J. A comparison of stated preference methods for environmental valuation. Ecol Econ. 1996;18(3):243-53.

14. Brown TC. Introduction to stated preference methods. In: Champ PA, Boyle KJ, Brown TC, editors. A primer on nonmarket valuation. Vol. 3. Dordrecht: Kluwer Academic Publishers, 2003. p. 99-110.

15. Whitehead J, Blomquist G. The use of contingent valuation in benefit-cost analysis. In: Alberini A, Kahn JR, editors. Handbook on contingent valuation. Cheltham: Edward Elgar Publishing Ltd.; 2006. p. 92-115.

16. Soekhai V, de Bekker-Grob EW, Ellis AR, Vass CM. Discrete choice experiments in health economics: past, present and future. Pharmacoeconomics. 2019;37(2):201-26.

17. Vass CM, Payne K. Using discrete choice experiments to inform the benefit-risk assessment of medicines: are we ready yet? Pharmacoeconomics. 2017;35(9):1-21.

18. Ancillotti M, Stefan Eriksson S, Andersson DI, Godskesen T, Nihlén Fahlquist J, Veldwijk J. Preferences regarding antibiotic treatment and the role of antibiotic resistance: a discrete choice experiment. Int J Antimicrob Agents. 2020;56(6):106198.

19. Roope LSJ, Buchanan J, Morrell L, et al. Why do hospital prescribers continue antibiotics when it is safe to stop? Results of a choice experiment survey. BMC Med. 2020;18(1):196.

20. Kistler CE, Beeber AS, Zimmerman S, et al. Nursing home clinicians' decision to prescribe antibiotics for a suspected urinary tract infection: findings from a discrete choice experiment. J Am Med Dir Assoc. 2020;21(5):675-82.e1.

21. Mott DJ, Hampson G, Llewelyn MJ, Mestre-Ferrandiz J, Hopkins MM. A multinational European study of patient preferences for novel diagnostics to manage antimicrobial resistance. Appl Health Econ Health Policy. 2020;18(1):69-79.

22. Bridges JF, Hauber AB, Marshall D, et al. Conjoint analysis applications in health: a checklist: a report of the ISPOR Good Research Practices for Conjoint Analysis Task Force. Value Health. 2011;14(4):403-13.

23. The Institute for Fiscal Studies. Charlesworth A, Johnson P editors. Securing the future: funding health and social care to the 2030s. 2018. https://ifs.org.uk/uploads/R143_Chapter4.pdf. Accessed 22 Jun 2021.

24. Mansfield C, Sutphin J, Boeri M. Assessing the impact of excluded attributes on choice in a discrete choice experiment using a follow-up question. Health Econ. 2020;29(10):1307-15.

25. Wallston KA, Wallston BS, DeVellis R. Development of the multidimensional development. Health Educ Monogr. 1978;6(2):160-70.

26. Wallston KA, Stein MJ, Smith CA. Form C of the MHLC Scales: a condition-specific measure of locus of control. J Pers Assess. 1994;63(3):534-53.

27. Johnson F, Lancsar E, Marshall D, et al. Constructing experimental designs for discrete-choice experiments: report of the ISPOR conjoint analysis experimental design good research practices task. Value Health. 2013;16:3-13.

28. Hauber AB, González JM, Groothuis-Oudshoorn CGM, et al. Statistical methods for the analysis of discrete choice experiments: a report of the ISPOR Conjoint Analysis Good Research Practices Task Force. Value Health. 2016;19(4):300-15.

29. Swait J, Louviere J. The role of the scale parameter in the estimation and comparison of multinomial logit models. J Mark Res. 1993;30(3):305-14. 
30. Hanemann M, Loomis J, Kanninen B. Statistical efficiency of double-bounded dichotomous choice contingent valuation. Am J Agric Econ. 1991;73(4):1255-63.

31. StataCorp. Stata statistical software: release 16. College Station (TX): StataCorp LP; 2019.

32. Whyte S, Harnan S. Effectiveness and cost-effectiveness of an awareness campaign for colorectal cancer: a mathematical modeling study. Cancer Causes Control. 2014;25(6):647-58.

33. Hinde S, McKenna C, Whyte S, et al. Modelling the cost-effectiveness of public awareness campaigns for the early detection of non-small-cell lung cancer. Br J Cancer. 2015;113(1):135-41.

34. Kesavayuth D, Poyago-Theotoky J, Zikos V. Locus of control, health and healthcare utilization. Econ Model. 2020;1(86):227-38.

35. Hajek A, König HH. Locus of control and frequency of physician visits: results of a population-based longitudinal study in Germany. Br J Health Psychol. 2017;22(3):414-28.

36. Arshad M, Mahmood SF, Khan M, Hasan R. COVID-19, misinformation, and antimicrobial resistance. BMJ. 2020;371:m4501.

37. Hsu J. How COVID-19 is accelerating the threat of antimicrobial resistance. BMJ. 2020;369:m1983.
38. Napolitano F, Izzo MT, Di Giuseppe G, Angelillo I. Public knowledge, attitudes, and experience regarding the use of antibiotics in Italy. PLoS ONE. 2013;8(12):e84177.

39. Determann D, Lambooij MS, Steyerberg EW, de Bekker-Grob EW, de Wit GA. Impact of survey administration mode on the results of a health-related discrete choice experiment: online and paper comparison. Value Health. 2017;20(7):953-60.

40. Vass CM, Boeri M. Mobilising the next generation of statedpreference studies: the association of access device with choice behaviour and data quality. Patient. 2021;14(1):55-63.

41. Hess S, Rose JM, Polak J. Non-trading, lexicographic and inconsistent behaviour in stated choice data. Transport Res Part D-Transport Environ. 2010;15(7):405-17.

42. de Bekker-Grob E, Donkers B, Jonker MF, Stolk EA. Sample size requirements for discrete-choice experiments in healthcare: a practical guide. Patient. 2015;8(5):373-84.

43. de Bekker-Grob EW, Donkers B, Bliemer MC, Veldwijk J, Swait JD. Can healthcare choice be predicted using stated preference data? Soc Sci Med. 2020;246:112736. 